Transportation Research Forum

Evaluating the Relationship Between Transportation Infrastructure and Economic Activity: Evidence from Washington State

Author(s): Steven K. Peterson and Eric L. Jessup

Source: Journal of the Transportation Research Forum, Vol. 47, No. 2 (Summer 2008), pp. 21-39

Published by: Transportation Research Forum

Stable URL: http://www.trforum.org/journal

The Transportation Research Forum, founded in 1958, is an independent, nonprofit organization of transportation professionals who conduct, use, and benefit from research. Its purpose is to provide an impartial meeting ground for carriers, shippers, government officials, consultants, university researchers, suppliers, and others seeking exchange of information and ideas related to both passenger and freight transportation. More information on the Transportation Research Forum can be found on the Web at www.trforum.org. 


\title{
Evaluating The Relationship Between Transportation Infrastructure and Economic Activity: Evidence from Washington State
}

\author{
by Steven K. Peterson and Eric L. Jessup
}

Prior analysis regarding transportation infrastructure has often focused on the aggregate effects of public investment on economic growth or activity, usually at a national or state level. Modeling efforts that attempt to treat all counties as equivalent units, while assuming a homogeneous modeling structure for all the units, may miss important information regarding the statistical and causal relationships between economic activity and transportation infrastructure. This study examines the interrelationships between infrastructure and activity using two Washington State highway infrastructure datasets in combination with county-level employment, wages, and establishment numbers for several industrial sectors for a subset of counties from 1990 to 2004. Estimates using vector autoregressions, error correction models, and directed acyclic graphs are made. The results show that the relationships between infrastructure investment and economic activity are often weak and are not uniform in effect.

\section{INTRODUCTION}

The question of public investment in transportation infrastructure is one of the oldest and most controversial issues since the ratification of the U.S. Constitution. The largest public infrastructure investment in transportation occurred as a result of the 1956 Interstate Highway Act and the subsequent authorization of the Department of Transportation in 1968. Holtz-Eakin (1993) estimated that almost $34.5 \%$ of all public capital investment has been in street and highway infrastructure, resulting in approximately $\$ 127$ billion in infrastructure investment since 1960 (Bureau of Transportation Statistics 2002).

In the last 15 years there has been increasing focus on the issue of infrastructure investment and its impact on the economy. Lakshmanan and Chatterjee (2005) note several types of infrastructure effects that are realized over different time scales. Brown (1999a, 1999b) posits highway investment as reducing transportation costs that then facilitates development of local area economies through changes in the scale and scope of the local economy. A study by Washington State University (Gillis and Casavant 1994), which includes interviews from nearly 650 business establishments in Washington, found that investment designed to improve freight efficiency and proximity to existing infrastructure was deemed "critical" for new development. Much of the prior analysis regarding infrastructure has focused on the aggregate effects of public investment on economic growth or on development, usually at a national or state level. Modeling efforts that attempt to treat all counties as equivalent units, while assuming a homogeneous modeling structure for all the units, may miss important information regarding the statistical and causal relationships between economic activity and transportation infrastructure.

\section{LITERATURE REVIEW}

Gramlich (1994) identifies public infrastructure capital as "large capital intensive natural monopolies such as highways, other transportation facilities, water and sewer lines, and communication systems." An alternative definition simply states public infrastructure is the tangible capital stock owned by the public sector. The first recent study examining the role of public capital infrastructure on economic 
growth was Aschauer (1989), which found a positive relationship between infrastructure investment and economic productivity. Additional studies were conducted by Munnell (1990, 1992), which appeared to confirm Aschauer's original findings. Several studies (Tatom 1991; Dalenberg and Partridge 1995; Dalenberg and Partridge 1997) challenged the results of Aschauer and Munnell, indicating they had overstated the impact of public capital investment on economic growth. Instead, they found that the positive benefits of public investment were either small or statistically insignificant. This has led one author (Fisher 1997), in a comprehensive review of the topic, to conclude that "some public services clearly have a positive effect on some measures of economic development in some cases" (emphasis in the original).

One commonality shared by these studies is that they all use a production function modeling approach. As noted in Fisher (1997) most of these studies are also aggregated at the state level, while a few examine local areas (Reynolds and Maki 1990; Luce 1994; Dalenberg and Partridge 1995). Reynolds and Maki (1990) specifically examine labor market areas which are associated with particular metropolitan areas.

Fox and Porca (2001) note infrastructure is commonly held to be public investment that improves the productivity of the private sector, but the investment may also be viewed in terms of services rendered. A similar concept is noted in Lakshmanan and Anderson (2002), where the authors detail the linkages between transportation policy, information technologies, infrastructure investment, and economic activity associated with (freight) transportation services.

In most prior studies, relevant variables are derived from highly aggregated data, such as total highway spending or total public capital as measured in highway miles. Economic development indicators include such measures as state gross product, employment, foreign investment, number of new plants, or personal income. The production function analysis approach relies heavily on aggregated data, even for estimations done at the local level. Accordingly, estimation results using disaggregated data may provide additional information on local conditions resulting from infrastructure investment.

An alternative, cost-focused approach (Chandra and Thompson 2000) examining public transportation investment was undertaken that examined the impact of investment in rural highways on non-urban counties in the United States between 1969 and 1993. The authors proceed from the hypothesis that highway capital may provide benefits to specific industries within a region over competitors in other regions. A model is developed in which multiple routes exist in the transportation network with customers and firms located at various positions on the network. The model predicts the impact on firm growth within a region due to lowered transportation costs through the mechanism of market area expansion or contraction. Further, they assume empirically that lower transportation costs will occur on those routes that receive infrastructure investment. The authors then estimate an empirical fixed-effects econometric model with county-level industry earnings determined by Standard Industrial Classification (SIC) codes as the outcome variable with a matrix of highway construction variables as the primary input.

One possible shortcoming in the approach used in Chandra and Thompson (2000) is the assumption of homogeneity within counties. Counties are not uniformly shaped structures of equal area spaced regularly across the landscape. A priori one would not expect that transportation infrastructure would have an equally beneficial effect on all locations within a county, or an equally deleterious effect on counties that do not receive infrastructure investment but have locations proximate to the investment. Instead, one would expect that intra-county and inter-county effects that are a function of proximity to the infrastructure would exist.

Spatial interaction models are another method of assessing infrastructure impacts on economic activity. These models seek to approximate processes that happen over space; regarding transportation, they usually model commodity or traffic flows in a networked space. Examples of such models are outlined in Haynes and Fotheringham (1984) and Fotheringham et al. (2001). Spatial interaction models approximate changes in economic activity resulting from infrastructure improvements by 
assessing the changes in flows between locations in the spatial network. These changes in flows, or accessibility, can be associated with increases in factor productivity (Fox and Porca 2001).

Spatial interaction models are particularly well suited for estimating the economic impacts of transportation infrastructure investment if the origin and destination traffic counts are known, or can be reliably estimated. Two recent examples of accessibility measure analysis can be found in Baradaran and Ramjerdi (2001), which examines locational accessibility of European cities, and in Vachal et al. (2004), where accessibility measures are used to inform a set of transportation quality indices for non-urban/rural communities in the United States. In the absence of the required parameter data, the applicability of these models lessens considerably.

A final consideration in the estimation of infrastructure investment impacts on economic activity is the nature of the causal relationship. Economic development may induce investment in transportation infrastructure, infrastructure investments may accommodate expansion of economic activity, or it may be a mix of both effects. In order to examine and estimate changes in economic activity due to infrastructure investment, an empirical model describing the system must first be developed. Variables of interest could be changes in total employment in the area, changes in employment by industry classification, changes in total personal income, income by industry, changes in population, the number of business openings or closings, and changes in area property values at the census tract level. As noted in a recent study (Smith et al. 2002), the causeeffect relationship between transportation investment and economic activity may also change over time. As a result, the causal relationship between infrastructure investment and economic activity is not straightforward and may involve feedbacks with autoregressive components, simultaneity, and various leading and lagging effects between the variables in the system. In order to ascertain the nature of these interrelationships different estimation and statistical inference techniques need to be considered and employed.

\section{METHODOLOGY}

Due to the simultaneity, endogeneity and autoregressive properties that are likely to be present in the variables of interest, the modeling format chosen to examine these interrelationships is a vector autoregression (VAR). VARs are quite common in applied econometrics, but their use in infrastructure analysis has been limited. Two recent examples are Sturm et al. (1999), that examines long-term output effects from infrastructure investment, and Kawakami and Doi (2004), which uses a VAR and vector error correction (VEC) framework to examine the economic effects of investment in port infrastructure in Japan. The estimation framework proceeds as a VAR/VEC model with associated impulse response functions (IRFs). IRFs measure the degree of response, or change, in a variable that results from an exogenous shock.

The VAR model consists of a series of Ordinary Least Squares (OLS) regressions in which each dependent variable is a function of the independent variables and lagged values of the dependent and independent variables, including an uncorrelated error term. In addition, due to the assumption of endogeneity, each response variable in the system is also an independent variable for the other dependent variables in the system (Enders 1995). Vector autoregression models are particularly adept at describing the data involved in a system and in forecasting. However, the identification of the causal structure of a system usually must rely upon a priori economic theory (Stock and Watson 2001). The associated impulse responses then serve to describe the historical association between the different variables in the system.

A variant of the standard vector autoregression model is the vector error correction model, or VECM. This family of vector autoregressions allows for the modeling of nonstationary systems. Stationarity is the assumption that a process does not vary in the mean or variance over time. By implication it is assumed that the error terms of the VAR system of equations are also stationary (Enders 1995). However, most time series of variables exhibit a seasonal or temporal trend that violates the stationarity assumption. By de-trending the data (usually by taking using the 
change in levels of a variable, or differencing) a stationary system can be derived for estimation. Vector error correction models allow for series of variables that may be nonstationary, but have a linear combination between the variables that is stationary. This type of stationarity is defined as cointegration, or a cointegrated series (Engle and Granger 1987). In effect, cointegration describes the tendency for two variables to follow similar paths, or trends, over time. Cointegration is then described according to the rank or order of integration between variables. By differencing a series $d$ times, a stationary process can be identified in which the series is cointegrated of order $d$.

Associated with vector autoregressions is the notion of Granger causality (Granger 1969), which is a measure of statistical association between two variables. This statistical measure has been criticized as weak and perhaps misleading (Garrison 1988; Toda and Phillips 1993). The danger in this measure is the temptation to fall into the logical fallacy of post hoc ergo prompter hoc, in which correlation between two variables is given the erroneous implication of causation simply due to the realization of one variable prior to the occurrence of another variable. Due to the ambiguity surrounding measures of Granger causation, these statistics will not be considered in this study.

In contrast to the strict temporal precedence relationship of Granger causality, other statistical methods exist that provide an improvement in determining causal relationships between variables. Recent advances in methodology have posited the use of directed acyclic graphs (DAGs) in order to obtain additional information on any causal relationships that may exist between the variables in a vector autocorrelation model (Glymour et al. 1987). DAG application assumes that the relationships in a system of variables can be represented as a type of graph. Causation can then be represented graphically as a directional arc or linear connection between two or more variables in the system. Further, the information on causality may be determined from the statistical relationships that exist between the residuals contained in the correlation matrices of vector autocorrelation models (Bessler et al. 2002).

\section{STUDY AREA}

This study proposes to examine the effects of transportation infrastructure at the local level over time and differentiating these effects by the type of highway infrastructure and the rural-urban character of the county. Counties in Washington State were first identified as major urban, small urban, or rural. This characterization is based upon the U.S. Office of Management and Budget urban-rural classifications and then further identified using the Rural Urban Commuting Area (RUCA) area definitions (Washington State Department of Health 2006). Large urban counties are those with urban populations greater than 100,000, while small urban counties have urbanized populations between 25,000 and 100,000. Rural counties are defined as those counties that do not have urbanized population concentrations greater than 25,000. Infrastructure was then classified as major highway or minor highway based upon annual traffic count volumes for the primary traffic arterials in the county (Peterson et al. 2004). A county-highway combination, such as urbanmajor highway, rural-major highway, etc., further differentiates the counties. The counties chosen represent a reasonable geographic and demographic cross-section of urban, small-urban, and rural Washington counties. Further, they all had some type of transportation infrastructure investment that was readily identifiable in the available data sets from which to construct a reliable time series. Table 1 provides a listing of the counties, their designation, and the associated highway types. 
Table 1: Study Counties, Types and Highway Types

\begin{tabular}{lcl}
\hline County & Type & Highway Type \\
\hline Clark & large urban & major highway \\
Grant & rural & major highway \\
Grays Harbor & rural & minor highway \\
Lincoln & rural & major highway \\
Pend Oreille & rural & minor highway \\
Spokane & large urban & major highway \\
Yakima & small urban & major highway \\
\hline
\end{tabular}

\section{DATA}

Broad economic activity variables from the Quarterly Census of Employment and Wages (QCEW) for 1990 through Q1 of 2005 (Bureau of Labor Statistics 2006) were used to measure economic changes at the county level. This dataset provides information on levels of employment, average wages, and the number of establishments according to SIC or NAICS business activity classifications. The industrial classes deemed to be most affected by transportation infrastructure were agriculture production, mining, manufacturing, retail, wholesale trade, construction, and warehousing/ transportation. Other classes, such as real estate, fire and insurance, professional and technical services, educational services, and health care, were viewed as "footloose" sectors that are not as dependent upon transportation infrastructure and accessibility. Further, the QCEW dataset was chosen due to temporal contiguity with two infrastructure databases obtained from the Washington State Department of Transportation. These are the Construction Contract Information System (CCIS) and the Capital Program Management System (CPMS). Both datasets have information on infrastructure expenditures, including locations and types of completed investments from 1991 through 2004. Using a joined dataset, a cumulative infrastructure value was calculated for county expenditures on maintenance and repair projects or new capacity and connectivity construction projects. For capital projects crossing county lines, the investment amount was pro-rated using the ratio of in-county highway miles to the total highway miles affected by the project.

\section{EMPIRICAL MODEL AND STATISTICAL MEASURES}

Using the economic data in concert with cumulative investment, separate VAR systems of equations were created for each county-industry combination for the above-mentioned industries. The basic form of the VAR model using the QCEW and capital infrastructure investment data is

(1) $y_{t}=\mu+\sum_{k=1}^{p} \Pi_{k} y_{t-k}+\varepsilon_{t}$

$y_{t}$ is an $(n \times 1)$ column vector of $n$ dependent variables of establishments, wages and employment, at time $\mathrm{t}, \Pi_{k}$ is a coefficient matrix of the independent variables, $\mu$ is a vector of constants, and $y_{t-k}$ is a matrix of the lagged values of the dependent and independent variables, with $p$ being the lag length, while $\varepsilon_{t}$ is a matrix of serially uncorrelated error terms (Stock and Watson 2001).

Two important components of VAR estimation are the determination of series stationarity and the appropriate lag length, $p$, for each series. To determine stationarity and the order of cointegration, Dickey-Fuller and Augmented Dickey-Fuller tests were run for each county-industry pair. It was found that each series was stationary in first differences, or integrated of order 1 . The appropriate lag length for each $y_{t-k}$ was determined using Lutkepohlized (Lutkepohl 1990) estimates of the 
Likelihood Ratio, Akaike Information Criterion, Forecast Predicted Error, Bayes Information Criterion, and the Hannan and Quinn Information Criterion. The lag length chosen for each model used a "consensus of the statistics" approach. If there was no consensus lag length, the default was the lag length determined by the Likelihood Ratio statistic as likelihood methods provide generally reliable lag estimates in the absence of other information (Hubrich et al. 2001). Table 2 provides the lag lengths used in the VAR estimations for each county-industry pair.

Table 2: VAR/VEC Lag Lengths and Test Statistics by County and Industry

\begin{tabular}{|c|c|c|c|}
\hline County & Industry & Lag Length & Statistic \\
\hline \multirow[t]{7}{*}{ Clark } & Agricultural .Production & 11 & LR, FPE, AIC, HQIC \\
\hline & Mining & 3 & FPE, AIC \\
\hline & Construction & 9 & FPE, AIC \\
\hline & Manufacturing & 3 & FPE, AIC, HQIC \\
\hline & Wholesale & 3 & FPE, AIC \\
\hline & Retail & 12 & LR, FPE,AIC \\
\hline & Warehousing/Transport & 10 & FPE, AIC \\
\hline \multirow[t]{7}{*}{ Grant } & Agricultural .Production & 11 & FPE, AIC, HQIC \\
\hline & Mining & $\mathrm{N} / \mathrm{A}$ & \\
\hline & Construction & 1 & FPE, AIC, BIC \\
\hline & Manufacturing & 4 & FPE, AIC \\
\hline & Wholesale & 12 & LR, AIC \\
\hline & Retail & 3 & FPE, AIC \\
\hline & Warehousing/Transport & 12 & LR, FPE, AIC \\
\hline \multirow[t]{7}{*}{ Grays Harbor } & Agricultural .Production & 6 & FPE, AIC \\
\hline & Mining & $\mathrm{N} / \mathrm{A}$ & \\
\hline & Construction & 6 & FPE, AIC \\
\hline & Manufacturing & 3 & FPE, AIC, HQIC \\
\hline & Wholesale & N/A & \\
\hline & Retail & 12 & LR, FPE, AIC \\
\hline & Warehousing/Transport & 1 & FPE, AIC, HQIC, BIC \\
\hline \multirow[t]{7}{*}{$\overline{\text { Lincoln }}$} & Agricultural .Production & 12 & LR, FPE, AIC, HQIC \\
\hline & Mining & $\mathrm{N} / \mathrm{A}$ & \\
\hline & Construction & 9 & LR, FPE, AIC \\
\hline & Manufacturing & 9 & FPE, AIC \\
\hline & Wholesale & 12 & LR, FPE, AIC \\
\hline & Retail & 1 & FPE, AIC, HQIC, BIC \\
\hline & Warehousing/Transport & 3 & FPE, AIC \\
\hline \multirow[t]{7}{*}{ Pend Oreille } & Agricultural .Production & 12 & LR, AIC \\
\hline & Mining & N/A & \\
\hline & Construction & 12 & LR, AIC \\
\hline & Manufacturing & 10 & LR \\
\hline & Wholesale & N/A & \\
\hline & Retail & 1 & FPE, AIC, HQIC, BIC \\
\hline & Warehousing/Transport & 12 & LR, FPE, AIC, HQIC \\
\hline \multirow[t]{7}{*}{ Spokane } & Agricultural .Production & 11 & LR, FPE, AIC \\
\hline & Mining & 1 & FPE, AIC, HQIC, BIC \\
\hline & Construction & 12 & LR, FPE, AIC, HQIC \\
\hline & Manufacturing & 9 & FPE, AIC \\
\hline & Wholesale & 1 & FPE, AIC, HQIC, BIC \\
\hline & Retail & 12 & LR, FPE, AIC \\
\hline & Warehousing/Transport & 12 & LR \\
\hline
\end{tabular}


Table 2: (continued)

\begin{tabular}{llcl}
\hline Yakima & Agricultural Production & 11 & LR, FPE, AIC \\
Mining & N/A & \\
Construction & 12 & LR, FPE, AIC, HQIC \\
Manufacturing & 12 & LR \\
Wholesale & 11 & FPE, AIC \\
Retail & 12 & LR, FPE, AIC \\
Warehousing/Transport & 11 & LR, FPE, AIC, HQIC \\
\hline
\end{tabular}

A notation of N/A indicates that there were either no observations for that county-industry pair, or that the number of observations was insufficient to create lagged values. AIC=Akaike Information Criterion, $\mathrm{BIC}=$ Bayes Information Criterion, $\mathrm{FPE}=$ Forecast Predicted Error, HQIC=Hannan-Quinn Information Criterion, and LR=Likelihood Ratio.

Since the variable series were determined to be integrated of order 1 , denoted $I(1)$, we can difference the equation such that $\Delta y_{t}=y_{t-} y_{t-l}$. The VAR relationship in differences may then be written in error correction form as

(2) $\Delta y_{t}=\mu+\sum_{k=1}^{p-1} \Gamma_{k} \Delta y_{t-k}+\Pi y_{t-1}+\varepsilon_{t}$

where $\Gamma_{k}$ and $\Pi$ are coefficient matrices, and the rank $r^{1}$ (Enders 1995). If $r=0$, then $\Pi=0$, and the standard VAR model (1) is valid in first differences. However, if $\Pi \neq 0$, then the system will have $r<n$ cointegrating relationships, or $r$ possible linear combinations of $y_{i}$. Ignoring the cointegrating relationships leads to a VAR model that will be mis-specified (Johansen 1988).

In order to test for cointegration between variables, we examine the rank $r$ of $\Pi$ (Johansen and Juselius 1990). The rank of the $\Pi$ matrix is equal to the number of cointegrating vectors in the system and is affected by how the $\Pi$ term enters the system of variables. The order of cointegration can be statistically determined through the use of the trace statistic. ${ }^{2}$ Trace statistics test the null hypothesis of $r$ cointegrating vectors against the alternative of $p$ cointegrating vectors or the number of variables in the column vector $y_{t}$. Results for the trace test statistics indicating the cointegration rank are provided for each county in Table 3; the ranks were determined using the critical values from Osterwald-Lenum (1992). Results of N/A indicate a lack of data observations for a particular county-industry pair.

Table 3: Trace Test Statistics of Cointegration Rank by County

\begin{tabular}{lccccccc}
\hline County & Ag. Prod. & Mining & Const. & Manuf. & Whole. & Retail & Whse. \\
\hline Clark & 1 & 1 & 0 & 1 & 1 & 0 & 0 \\
Grant & 0 & N/A & 0 & 0 & 0 & 1 & 1 \\
Grays Harbor & 0 & N/A & 2 & 1 & N/A & 1 & 0 \\
Lincoln & $0 / 1$ & N/A & 0 & 0 & 1 & 0 & 2 \\
Pend Oreille & 0 & N/A & $0 / 1$ & 1 & N/A & 0 & $0 / 1$ \\
Spokane & $0 / 1$ & 0 & $0 / 1$ & 0 & $0 / 1$ & 1 & 2 \\
Yakima & 1 & N/A & 1 & 0 & 0 & $0 / 1$ & 0 \\
\hline
\end{tabular}

The cointegration rank results indicate that the arbitrary use of a single model framework for the estimation of the relationships between economic activity and transportation infrastructure is problematic and may lead to incorrectly specified models and/or problems with statistical inference applied uniformly to all counties within a state. One possible result is that the models are likely to be underspecified due to the absence of other explanatory variables in the system. 
Vector autoregression models produce output conducive to analysis by means of impulse response functions (IRFs). While IRFs are often used as a forecast estimation tool (Enders 1995; Stock and Watson 2001) they can also be used to understand the interrelationships that exist between variables in a system. IRFs rely upon the information contained in the error structure of the equations in a VAR system. These errors are often viewed as indicators of "innovation accounting" (Bessler 2002), in which the error structure reflects the responses of variables in the system due to shocks, or innovations, in one of the other system variables (the impulse). As a result, IRFs track the historical responses of variables in a system due to changes in the other system variables. In this regard, the IRFs are similar to measures of cross-elasticities of the response variables in the presence of a $1 \%$ change in the impulse variable. While an IRF is a forecast of probable future response, these forecasts are based on historical actuals. IRFs then describe how a system has responded in the past and how the system variables are interrelated.

A relatively new technique useful for determining causal relationships that can be estimated in the VAR framework is the implementation of directed graphs (Glymour et al. 1987; Yu et al. 2006). Directed graphs are part of general mathematical graph theory (Carre 1979; Spirtes et al. 1993), and can be implemented using the error correlation matrix of the VECMs (Bessler et al. 2002). Due to the likely presence of feedbacks within the system of variables being estimated here, a directed cyclic structural equation model (SEM) graph incorporating the errors, or shocks, in the system may provide insight into the causal relationships between the different variables, although the causal interpretation of recursive (cyclic) SEMs is not straightforward (Scheines et al. 1998). An alternative explanatory graph format uses non-recursive or acyclic directed graphs (Scheines et al. 1998; Yu et al. 2006), although this would imply causality in the system of equations estimated in the VAR is only one way and simultaneous feedbacks in the system are eliminated. Moreover, effects between the variables are contemporaneous. Directed acyclic graphs do provide a (qualified) base case for causal analysis, although the results should be interpreted with caution. As in Yu et al. (2006), the estimation of the directed graphs uses the TETRAD ${ }^{3}$ software program.

Directed Graphs operate under several primary assumptions (Scheines et al. 1998):

1. Causal Independence (Sufficiency) - no two variables are co-caused by an omitted variable; if $\mathrm{X}$ does not cause $\mathrm{Y}$, and $\mathrm{Y}$ does not cause $\mathrm{X}$, and there is no $\mathrm{Z}$ that causes both $\mathrm{X}$ and $\mathrm{Y}$, then $\mathrm{X}$ and $\mathrm{Y}$ are independent.

2. Faithfulness - zero correlation between variables is due to the absence of an edge between the variables and is not due to a structural cancellation of the parameters

3. Linearity - models are linear and additive in parameters

4. Uncorrelated, i.i.d. errors

5. No feedback

Bessler (2002) also notes two additional, related assumptions:

1. Markov Condition - probabilities can be determined by conditioning on the variable parents.

2. Normality - relates to items 3 and 4 , above.

The output of the DAG is a pattern that contains directed and undirected edges ${ }^{4}$. These edges are denoted as $\rightarrow$ for a directed edge, or without an arrowhead to indicate an undirected edge. Each directed edge in the graph represents a causal influence between two variables (Glymour et al. 1987). For example, a very simple pattern of $X \rightarrow Y$ indicates that $X$ causes $Y$, while the representation $X-Y$, indicates that a relation exists between $X$ and $Y$, but the direction of causality is not straightforward. Undirected edge relationships indicate simultaneity in the system variables, usually implying correlation without causation, but also the possible presence of system feedbacks.

A final consideration in the estimation of infrastructure investment impacts on economic activity is the nature of the causal relationship. Transportation infrastructure investment may be viewed theoretically as leading or lagging economic activity; economic development may induce investment in transportation infrastructure, infrastructure investments may accommodate expansion of economic activity, or it may be a mix of both effects. As noted in a recent study by Smith et al. (2002), the cause-effect relationship between transportation investment and economic activity may 
also change over time. As a result, the causal relationship between infrastructure investment and economic activity is not straightforward. The theoretical relationship between the variables involves feedbacks, simultaneity, and various leading and lagging effects between the variables in the system. A graphical example of the expected relationship between the system variables is given in Figure 1 .

Figure 1: Graph of the Theoretical Relationships Between System Variables

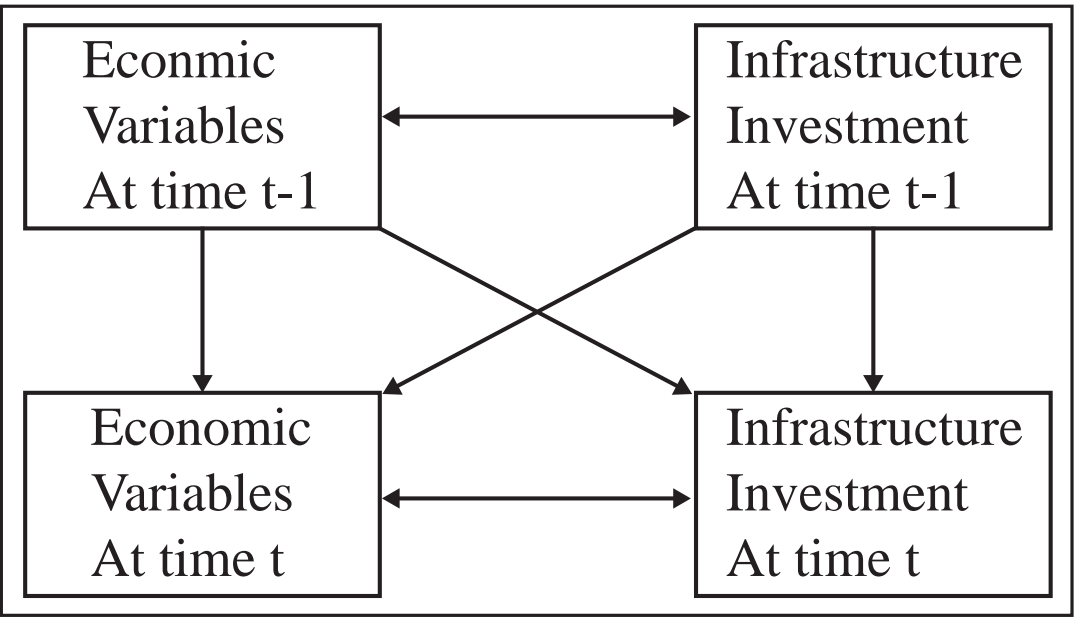

The presence of a simultaneous relationship between the variables represents a violation of the causal independence assumption (Spirtes et al. 1993). Also, as noted above, the model framework being estimated in this study does not hold strictly to Assumption 5. Although feedbacks in this system are temporally separated, i.e., the autoregressive properties of the system variables are realizable as separate estimators, Spirtes et al. (1993) mention that the development of a computationally feasible algorithm for graphical inference in the presence of causal insufficiency and feedback was an open problem in DAG research (p.360). As a result, the applicability of the results from the directed acyclic graphs may not be fully informed in those cases in which simultaneity is in effect, but such results should be quite close to the base case outlined by the acyclic graphs (Scheines et al. 1998). One other drawback to determining causality using DAGs is that the algorithms work best when data is linear and has a multivariate normal distribution.

\section{ESTIMATION RESULTS}

Tables 4 and 5 present the different estimation results for the counties in the study. The different economic variables are noted in the tables with the symbols_emp, _w, and _est, which represent employment, wages, and establishments, respectively; the variable cumulative infrastructure investment uses the symbol cuminv. The capital D denotes that the variables have been differenced. Not every industry is estimated in the same manner for every county due to variability in the presence or absence of cointegrating vectors in the data. If cointegrating vectors were found in the system of variables, the estimation proceeded using a VECM framework. Several of the counties did not have significant numbers of observations for some of the industrial classes in question, so the statistical relationships between economic activity in those sectors and infrastructure investment are unknown. The models were estimated using first differences, or changes, in the levels of the variables. The models estimate the impact of changes in economic variables due to changes in infrastructure investment and vice versa. Statistical significance is determined at the $90 \%$ significance level $(p<0.10)$ unless otherwise stated. Significant VAR and VEC results for investment and economic activity are presented in Table 4. 
Transportation Infrastructure

Table 4: Significant VAR and VECM Results By County

\begin{tabular}{|c|c|c|c|c|}
\hline County & Equation & R-sq & chi2 & $\mathbf{P}$ \\
\hline \multirow[t]{6}{*}{ Clark } & D_min_oil_w & 0.17 & 34.99 & 0.00 \\
\hline & D_cuminv & 0.09 & 16.51 & 0.09 \\
\hline & D.whse_trans_emp & 0.46 & 146.30 & 0.00 \\
\hline & D.whse_trans_w & 0.54 & 202.04 & 0.00 \\
\hline & D.whse_trans_est & 0.39 & 110.09 & 0.00 \\
\hline & D.cuminv & 0.40 & 110.45 & 0.00 \\
\hline County & Equation & R-sq & chi2 & $\mathbf{P}$ \\
\hline \multirow[t]{12}{*}{ Grant } & D.agprod_emp & 0.93 & 2026.36 & 0.00 \\
\hline & D.agprod_w & 0.79 & 524.07 & 0.00 \\
\hline & D.agprod_est & 0.52 & 152.82 & 0.00 \\
\hline & D.cuminv & 0.30 & 60.69 & 0.05 \\
\hline & D.whole_emp & 0.56 & 181.92 & 0.00 \\
\hline & D.whole_w & 0.73 & 387.94 & 0.00 \\
\hline & D.whole_est & 0.38 & 88.67 & 0.00 \\
\hline & D.cuminv & 0.34 & 71.88 & 0.01 \\
\hline & D_retail_w & 0.29 & 56.96 & 0.00 \\
\hline & D_cuminv & 0.19 & 33.11 & 0.00 \\
\hline & D_whse_trans_w & 0.62 & 160.98 & 0.00 \\
\hline & D_cuminv & 0.49 & 93.46 & 0.00 \\
\hline County & Equation & R-sq & chi2 & $\mathbf{P}$ \\
\hline \multirow[t]{9}{*}{ Grays Harbor } & D_construct_emp & 0.39 & 87.87 & 0.00 \\
\hline & D_construct_w & 0.47 & 117.70 & 0.00 \\
\hline & D_construct_est & 0.24 & 42.38 & 0.01 \\
\hline & D_cuminv & 0.34 & 71.08 & 0.00 \\
\hline & D_manuf_w & 0.65 & 278.18 & 0.00 \\
\hline & D_cuminv & 0.30 & 62.18 & 0.00 \\
\hline & D_retail_emp & 0.62 & 173.43 & 0.00 \\
\hline & D_retail_w & 0.57 & 142.11 & 0.00 \\
\hline & D_cuminv & 0.48 & 99.89 & 0.00 \\
\hline County & Equation & R-sq & chi2 & $\mathbf{P}$ \\
\hline \multirow[t]{15}{*}{ Lincoln } & D_agprod_emp & 0.87 & 596.63 & 0.00 \\
\hline & D_agprod_w & 0.69 & 193.23 & 0.00 \\
\hline & D_agprod_est & 0.67 & 179.26 & 0.00 \\
\hline & D_cuminv & 0.58 & 123.93 & 0.00 \\
\hline & D.construct_emp & 0.45 & 110.55 & 0.00 \\
\hline & D.construct_w & 0.54 & 162.77 & 0.00 \\
\hline & D.construct_est & 0.36 & 76.08 & 0.00 \\
\hline & D.cuminv & 0.51 & 139.92 & 0.00 \\
\hline & D manuf_emp & 0.57 & 176.84 & 0.00 \\
\hline & D manuf_w & 0.69 & 308.34 & 0.00 \\
\hline & D manuf_est & 0.30 & 59.16 & 0.01 \\
\hline & D.cuminv & 0.34 & 70.45 & 0.00 \\
\hline & D_whole_emp & 0.53 & 113.82 & 0.00 \\
\hline & D_whole_w & 0.48 & 95.03 & 0.00 \\
\hline & D_cuminv & 0.36 & 57.41 & 0.01 \\
\hline
\end{tabular}


Table 4: (continued)

\begin{tabular}{|c|c|c|c|c|}
\hline County & Equation & R-sq & chi2 & $\mathbf{P}$ \\
\hline \multirow[t]{12}{*}{ Pend Oreille } & D.agprod_emp & 0.60 & 179.80 & 0.00 \\
\hline & D.agprod_w & 0.65 & 227.68 & 0.00 \\
\hline & D.agprod_est & 0.57 & 158.98 & 0.00 \\
\hline & D.cuminv & 0.37 & 70.85 & 0.02 \\
\hline & D_construct_emp & 0.53 & 85.65 & 0.00 \\
\hline & D_construct_w & 0.63 & 131.84 & 0.00 \\
\hline & D_construct_est & 0.60 & 112.38 & 0.00 \\
\hline & D_cuminv & 0.49 & 71.68 & 0.01 \\
\hline & D_manuf_emp & 0.47 & 79.25 & 0.00 \\
\hline & D_manuf_w & 0.68 & 189.26 & 0.00 \\
\hline & D_manuf_est & 0.58 & 124.62 & 0.00 \\
\hline & D_cuminv & 0.40 & 59.61 & 0.00 \\
\hline County & Equation & R-sq & chi2 & $\mathbf{P}$ \\
\hline \multirow[t]{18}{*}{ Spokane } & D_agprod_emp & 0.68 & 208.85 & 0.00 \\
\hline & D_agprod_w & 0.62 & 159.58 & 0.00 \\
\hline & D_agprod_est & 0.36 & 56.27 & 0.07 \\
\hline & D_cuminv & 0.46 & 82.01 & 0.00 \\
\hline & D min_oil_emp & 0.06 & 9.76 & 0.04 \\
\hline & D.cuminv & 0.07 & 11.06 & 0.03 \\
\hline & D_construct_emp & 0.91 & 924.72 & 0.00 \\
\hline & D_construct_w & 0.90 & 816.33 & 0.00 \\
\hline & D_construct_est & 0.52 & 101.25 & 0.00 \\
\hline & D_cuminv & 0.48 & 86.26 & 0.00 \\
\hline & D manuf_emp & 0.38 & 85.93 & 0.00 \\
\hline & D manuf_w & 0.79 & 515.34 & 0.00 \\
\hline & D manuf_est & 0.38 & 87.80 & 0.00 \\
\hline & D.cuminv & 0.26 & 49.04 & 0.07 \\
\hline & D_whole_w & 0.14 & 23.73 & 0.00 \\
\hline & D_cuminv & 0.10 & 16.52 & 0.00 \\
\hline & D_retail_emp & 0.70 & 217.65 & 0.00 \\
\hline & D_cuminv & 0.40 & 61.24 & 0.07 \\
\hline County & Equation & R-sq & chi2 & $\mathbf{P}$ \\
\hline \multirow[t]{7}{*}{ Yakima } & D_construct_emp & 0.86 & 537.05 & 0.00 \\
\hline & D_construct_w & 0.86 & 542.04 & 0.00 \\
\hline & D_construct_est & 0.42 & 64.94 & 0.03 \\
\hline & D_cuminv & 0.49 & 87.57 & 0.00 \\
\hline & D.whse_trans_emp & 0.76 & 423.97 & 0.00 \\
\hline & D.whse_trans_w & 0.86 & 835.93 & 0.00 \\
\hline & D.cuminv & 0.35 & 73.94 & 0.00 \\
\hline
\end{tabular}

The Construction sector has the most consistent results across all of the counties. Infrastructure investment and economic variables are significant in five of the seven counties: Grays Harbor, Lincoln, Pend Oreille, Spokane, and Yakima. Manufacturing also had at least one significant relationship in four of the study counties. Manufacturing was significant in Grays Harbor, Lincoln, Pend Oreille, and Spokane counties. While Spokane is the industrial and commercial center 
for eastern Washington, the impact of transportation infrastructure on wages, employment, and establishment numbers in Lincoln and Pend Oreille is interesting. These counties are directly to the west and north of Spokane County, so transport infrastructure investment may be facilitating a shift in manufacturing operations outside of urban areas into the more rural areas of Lincoln and Pend Oreille Counties, a national and regional process that has attracted the attention of researchers since the 1990s (Kandel and Brown 2006).

The agricultural production sector is found to be significant for all the economic variables and roadway investment in Grant, Lincoln, Pend Oreille, and Spokane counties. Grant and Lincoln are part of the agricultural "heartland" of Washington State, while Pend Oreille is a forest products production center. Notably, the exceptions are in Grays Harbor and Yakima counties, which are, respectively, major forest products and agricultural producing counties in Washington State.

The results for the other county-sector pairs are generally mixed. Several county-industry pairs indicate all four system variables were significant, while others show that only a few of the economic variables are associated with changes in infrastructure investment. In these sectors, the most common significant economic variable affected by transportation infrastructure investment is the sectoral wage rate. In Clark County, wages in the mining and warehousing sectors are significant, while in Grant County, wages were significantly affected not only in agriculture, but in the wholesaling, retail, and warehousing and transportation sectors. In Grays Harbor County, wages were affected in manufacturing and retail, while in Lincoln County, the wage rates in the manufacturing and wholesale sectors were impacted by infrastructure investment. Spokane County experienced wage effects in the wholesale sector in addition to the other sectors already mentioned, while Yakima had wage effects in the warehousing and transportation sector.

One of the most interesting findings is the minor effect of transportation infrastructure investment on the warehousing and transportation sector and the wholesaling sector. Warehousing and transportation employment, wage rates, and establishment numbers were only found to have a significant relationship with infrastructure investment in Clark County. This may indicate that Vancouver, Washington, is serving as the warehousing and distribution location in the Portland, Oregon, metropolitan area as high land costs in Portland spur land use changes and changes in the pattern of economic activity between the two cities. Yakima County had significant effects with employment and wages in the warehousing and transportation sector, but no significant effect on establishment counts. Effects on wholesaling were greatest in Grant and Lincoln counties. This could reflect the lower costs of wholesaling operations in these mostly rural counties, or perhaps firms seeking locational advantages by operating in the center of the state.

While employment is also found to be significantly associated with infrastructure investment in several of the county-industry pairs, investment effects on establishments are found to be significant only in the presence of the sectoral employment and wage variables. In addition to the county-industry pairs described previously, the employment-infrastructure relationship was found to be significant in the retail sector in Grays Harbor and Spokane counties and employment changes in the mining sector in Spokane County. Since Spokane is the commercial and retail hub of eastern Washington, transportation infrastructure investment would be expected to have some effect on the retail sector, with employment perhaps a derivative effect of greater accessibility to retail establishments resulting from transportation investment. While Grays Harbor is not a large commercial hub, it does have a large tourism component that is likely reflected in the retail employment effects.

Finally, most of the systems indicating a significant association between economic activity and infrastructure investment have long lag periods, usually on the order of 11 or 12 months. These long lag periods may indicate that industries do not alter their business, employment, and wage decisions immediately in response to changes in transportation investment, but accommodate these changes over a longer time horizon. This would also suggest that transportation demand-driven changes in infrastructure investment take time to be implemented and have a significant impact on local economies. Finally, the $\mathrm{R}^{2}$ values are generally quite good in those systems in which all of the variables are significant. $\mathrm{R}^{2}$ values decline substantially in the presence of only one or two 
significant economic variables. These results indicate that the vector autoregression models explain a large amount of the variation in each system, but that other unspecified variables also contribute significantly to the system dynamics.

While the VAR models indicate the presence of significant relationships among many of the county-industry pairs and in infrastructure investment, the direction of causality in the relationships is not necessarily clear. Causal or other relationships detected by the use of directed acyclic graphs are presented in Table 5. An arrow symbol indicates a causal relationship, while an undirected edge denoted by a - symbol indicates that the exact causal nature cannot be determined. Such an ambiguity in the system suggests the presence of simultaneity or causal feedbacks between the variables in the system. Feedbacks imply that current levels of the variables, or rates of change, are dependent upon the changes of the other variables in the relationship. For example, if the relationship is noted as "establishments - investment," the implication would be that changes in the number of establishments in a sector are responsive to changes in infrastructure investment. In turn, these changes in establishment counts influence a response in infrastructure expenditures. This may indicate that the relationship between the two variables may be simultaneously reinforcing. It is also possible that the exact causal relationship is unclear, perhaps due to the influence of an unknown, latent variable that is not specified in the model. The statistical level of significance for the presence of a causal relationship is set at 0.05 , unless otherwise noted. The DAGs were run for the economic variables and infrastructure investment by industrial sector. The results, therefore, provide insight into the causal relationships between the variables for the specific counties only.

Table 5: Significant Directed Acyclic Graph Results

\begin{tabular}{lll}
\hline County & Industry & Causal Relationship \\
\hline Clark & Retail & investment --> employment \\
Grant & Construction & investment --> employment \\
Grays Harbor & & None \\
Lincoln & & None \\
Pend Oreille & Construction & wages -- investment \\
Pend Oreille & Retail & establishments -- investment \\
Spokane & Warehousing/Transport & investment --> establishments \\
Yakima & Agricultural Production & employment -- investment \\
\hline
\end{tabular}

As a result of the likely presence of simultaneity in the systems of variables, the DAG results indicating significant causal relationships between infrastructure and economic activity are far fewer than the VAR results. Only six relationships are discovered using the DAG process, three indicating a direct causal relationship, and three providing unclear results. Investment is found to influence retail sector employment in Clark County and construction sector employment in Grant County. Investment is also found to be a causal driver of establishment numbers in the Spokane Warehousing sector, while a probable simultaneous relationship is noted between agricultural production employment and investment in Yakima County. Interestingly, VAR/VEC estimations do not indicate significant statistical associations for any of these county-industry pairs. No causal relationships were found for any of the sectors in Grays Harbor or Lincoln counties.

The following two relationships are discovered for Pend Oreille County: one between retail establishments and roadway investment and one between construction sector wages and investment. Only the construction result is substantiated by the results of the VAR estimation. A complete graph for Pend Oreille County is provided in Table 6. A further examination of the VAR results, the DAGs, and the impulse responses for this county is detailed. 
Transportation Infrastructure

Table 6: Pend Oreille County Directed Acyclic Graph Results

\begin{tabular}{ll}
\hline Industry & Causal Relationship \\
\hline Agricultural Production & employment -- establishments \\
& wages -- establishments \\
Construction & wages -- investment \\
Manufacturing & wages -- establishments \\
Retail & employment -- wages \\
& establishments -- investment \\
Warehousing/Transport & employment -- wages \\
& employment -- establishments \\
& wages -- establishments \\
\hline
\end{tabular}

Results are significant at the $10 \%$ level. Bold relationships are significant at the $5 \%$ level.

The final piece of analysis involves the use of impulse response functions (IRFs). Combined with the results achieved in the vector autoregressions, the IRFs provide information on the direction and magnitude of response to changes in one of the other system variables. A graph of the IRF provides an impulse and a response variable, with the magnitude of change on the vertical axis and the response period (step) in months on the horizontal axis. As the study is concerned with the interrelationship between changes in economic activity and infrastructure investment, a cumulative measure is more appropriate to measure the persistence of the effects of changes to the system over time (Andrews and Chen 1994). A cumulative IRF (CIRF) measures the amount of time it takes for a variable to converge (in this case, $\Delta=0$, or no change), subsequent to a shock in the system (Marques 2004). If an IRF does not trend back towards zero over the period, the system has either permanently shifted, perhaps to a new equilibrium point, or the adjustment period is longer than the time period under consideration. The systems estimated in this study allowed for a maximum lag period of 12 months. For the measures of persistence, an additional 12 months was allowed in estimating the CIRFs, for a total of 24 months. CIRF results are presented below for one industry-county economic variable pairing, which is construction sector wages and infrastructure investment in Pend Oreille County, as part of an extended example comparing the significant vector autoregression, directed acyclic graph, and impulse response function results.

\section{Pend Oreille County Construction Sector CIRF}

Pend Oreille County is a primarily rural county located in the forests and mountains of northeastern Washington State. Transportation infrastructure is primarily small state highways and county or forest service roads. Pend Oreille County also features one of a number of small border crossings into Canada that exist in eastern Washington.

Based upon the results of the VAR/VEC and DAG routines, construction sector wages and infrastructure investment in the county are characterized by the presence of simultaneity and a probable dual-causal relationship existing over a lagged period of 12 months. An examination of the CIRFs for these variables in Figure 2 provides some visual confirmation of this interrelationship.

The CIRF of wage effects on infrastructure investment indicates that increases in the sector wage rate are associated with a permanent increase in infrastructure investment. This increase peaks after 15 months and then declines through month 24. At the same time, an increase in infrastructure expenditures is associated with a modest decline in the wage rate for the first five to six months after a change, which is then followed by a permanent increase in the wage rate out to 24 months. It should be noted that the changes in the wage rate are quite modest. A $1 \%$ change in the rate of investment translates into a change in the wage rate of $0.00015 \%$ after 18 months. 
Figure 2: Impulse and Response Functions: Investment and Construction Wages in Pend Oreille County

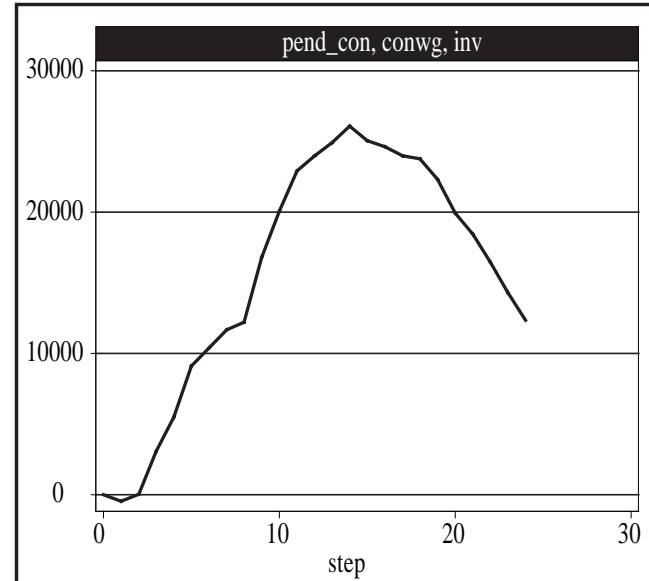

Graphs by irfname, impulse variable, and response variable

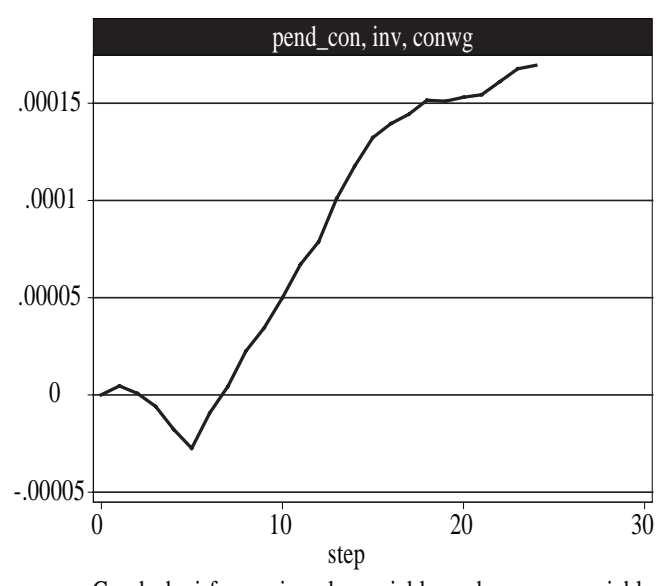

Graphs by irfname, impulse variable, and response variable

\section{DISCUSSION AND CONCLUSION}

The primary implications of this study are that counties are heterogeneous units that display remarkable diversity in economic responses to transportation infrastructure investment, and that infrastructure investment, at least during the 1990s and early 2000s, does little to alter already existing trends in economic activity within counties. Transportation infrastructure then appears to accommodate economic activity, but does little to reverse industry sector downturns or create substantial, long-term opportunities for expansion of a county's economic base.

The VAR and VECM results indicate that connections exist between many of the economic system variables and the cumulative level of investment in transportation. However, the variation among the county-industry pairs examined in this study is still substantial. The results also indicate the causal relationships between infrastructure and economic activity are not straightforward, but involve interactions between varying leads and lags of the system variables. The large amounts of unexplained variation in the system also point to other processes determining changes in economic activity, such as secular, industry-wide trends and infrastructure investment, perhaps as the result of political activity, such as lobbying that is separate from changes in the economic base of a county.

Directed acyclic graph results established that no direct causal relationships between infrastructure and economic activity could be detected in most of the various county-industry pairs. Where relationships are established, the results are often ambiguous and indicate again the presence of systemic feedbacks. The results appear to be a confirmation of Fisher's (1997) conclusion noted above, which is some transportation infrastructure investments have some effect on some economic indicators in some locations in Washington State.

The results of this research effort also point to the need for further investigation of the complex and dynamic relationships that might exist between investment in highway infrastructure and economic activity. This study looks at industry and investment interactions in isolation. Research into the interactions that may exist between the economic variables in different industries in addition to infrastructure investment may provide greater insight into growth and change at the local and regional level. This research would also benefit from additional analyses of other Washington State counties and perhaps the entire state. Studies undertaken using data from other states would also help to confirm the results of this study and establish a more general basis for the development of theory regarding the economic effects of capital investment in transportation. 
The results also call for a greater understanding of the extent of spatial effects arising from transportation infrastructure investment. This study examines county-wide effects on economic variables, but the effects of transportation investment may not have an equal effect across an entire county. It is reasonable to assume that the economic variables in question - employment, wages, and establishments - will be most affected in those areas in close proximity to the locations of infrastructure investment. A spatial-temporal study of firm starts and survival rates in the presence of transportation investment presents an opportunity to understand the spatial distribution of economic costs and benefits from infrastructure investment. Understanding the spatial limits of any economic effects would be a valuable tool for assessing the importance of capital investment to local and regional growth.

\section{Endnotes}

1. The rank of a matrix is the maximal number of independent columns or rows in the matrix (Mirsky 1990).

2. The trace statistic relies upon the trace of a matrix which is the sum of the elements of the main diagonal. It is also the sum of the eigenvalues of the matrix.

3. TETRAD is a free software download available from the Department of Philosophy at Carnegie Mellon University http://www.phil.cmu.edu/projects/tetrad/. Glymour et al. (1987) provides the introduction to TETRAD and causal structure modeling. The estimation routines for this study used the TETRAD III version of the software. TETRAD III implements the same PC algorithm used in TETRAD II as noted in Spirtes et al. (1993) and in Bessler et al. (2002).

4. In graph theory, edges specify a line joining two points or nodes, in the graph. In undirected graphs the edges are "unordered," while directed graphs have "ordered” edges. Edges are also often referred to as arcs, branches, or simply lines.

\section{References}

Andrews, D. W. K. and H. Y. Chen. “Approximately Median-Unbiased Estimation of Autoregressive Models.” Journal of Business and Economic Statistics 12 (2), (1994): 187-204.

Aschauer, D. A. “Is Public Expenditure Productive?” Journal of Monetary Economics 23, (1989): 177-200.

Baradaran, S. and F. Ramjerdi. "Performance of Accessibility Measures in Europe." Journal of Transportation and Statistics 4, (2/3), (2001): 31-48.

Bessler, D., J. Yang, and M. Wongcharupan. "Price Dynamics in the International Wheat Market: Modeling with Error Correction and Directed Acyclic Graphs.” Journal of Regional Science 42 (4), (2002): 793-825.

Bessler, D. "Directed Acyclic Graphs." PowerPoint presentation, (2002): http://agecon2.tamu.edu/ people/faculty/bessler-david/WebPage/Homepage.htm, accessed May 17, 2006.

Brown, D. M. "Highway Investment and Rural Economic Development: An Annotated Bibliography.” Bibliographies and Literature of Agriculture, No. 133, U.S. Department of Agriculture, Economic Research Service, (1999a). 
Brown, D. M. "Will Increased Highway Funding Help Rural Areas?” Agricultural Information Bulletin No. 753, U.S. Department of Agriculture, Economic Research Service, (1999b).

Carre, Bernard. Graphs and Networks. Clarendon Press, Oxford, 1979.

Chandra, A. and E. Thompson. "Does Public Infrastructure Affect Economic Activity? Evidence from the Rural Interstate Highway System." Regional Science and Urban Economics 30, (2000): 457-490.

Dalenberg, D. R. and M. D. Partridge. "The Effects of Taxes, Expenditures, and Public Infrastructure on Metropolitan Area Employment.” Journal of Regional Science 35 (4), (1995): 617-644.

Dalenberg, D. R. and M.D. Partridge. "Public Infrastructure and Wages: Public Capital’s Role as a Productive Input and Household Amenity.” Land Economics 73 (2), (1997): 268-284.

Enders, W. Applied Econometric Time Series. John Wiley and Sons, New York, 1995.

Engle, R. and C. Granger. "Co-integration and Error Correction: Representation, Estimation and Testing.” Econometrica 55 (2), (1987): 251-276.

Fisher, R. C. "The Effects of State and Local Public Services on Economic Development." New England Economic Review March/April, (1997): 53-82 (including discussion).

Fotheringham, A. S., C. Brunsdon, and M. Charlton. Quantitative Geography. Sage Publications, Thousand Oaks, CA, 2001.

Fox, W. F. and S. Porca. "Investing in Rural Infrastructure." International Regional Science Review 24 (1), (2001): 103-133.

Garrison, R. "On the Issue of Causality in Modern Empirical Economics.” The Austrian Economics Newsletter 9 (3) Spring/Summer, (1988): 7-8.

Gillis, W. and K. Casavant. "Linking Transportation Improvements to New Business Development in Eastern Washington." Eastern Washington Intermodal Transportation Study, Research Report 1, School of Economic Sciences, Washington State University, 1994.

Glymour, C., R. Scheines, P. Spirtes, and K. Kelly. Discovering Causal Structure: Artificial Intelligence, Philosophy of Science, and Statistical Modeling. Academic Press, San Diego, CA., 1987.

Gramlich, E. M. “Infrastructure Investment: A Review Essay.” Journal of Economic Literature 32, (1994): 1176-1196.

Granger, C. "Investigating Causal Relations by Econometric Models and Cross-Spectral Methods." Econometrica 37, (1969): 424-438.

Haynes, K. E. and A. S. Fotheringham. Gravity and Spatial Interaction Models. Vol. 2, Sage Series in Scientific Geography, Sage Publications, Beverly Hills, CA, 1984.

Holtz-Eakin, D. "State-specific Estimates of State and Local Government Capital.” Regional Science and Urban Economics 23, (1993): 185-209.

Hubrich, K., H. Lutkepohl, and P. Saikkonen. "A Review of Systems Cointegration Tests." Econometric Reviews 20 (3), (2001): 247-318. 
Johansen, S. "Statistical Analysis of Cointegration Vectors." Journal of Economic Dynamics and Control 12, (1988): 231-254.

Johansen, S. and K. Juselius. "Maximum Likelihood Estimation and Inference on Cointegration - with Applications to the Demand for Money." Oxford Bulletin of Economics and Statistics 52, (1990): 169-210.

Kandel, W.A. and D.L. Brown. Population Change and Rural Society. Springer, Dordrecht, The Netherlands, 2006.

Kawakami, T. and M. Doi. "Port Capital Formation and Economic Development in Japan: A Vector Autoregression Approach.” Papers in Regional Science 83, (2004): 723-732.

Lakshmanan, T.R. and W. P. Anderson. "Transportation Infrastructure, Freight Services Sector and Economic Growth." Center for Transportation Studies, Boston University, a White Paper prepared for the Federal Highway Administration, U. S. Department of Transportation, (2002).

Lakshmanan, T.R. and L. R. Chatterjee. "Economic Consequences of Transport Improvements.” Access 26, (2005): 28-33.

Luce, T. F., Jr. "Local Taxes, Public Services, and the Intrametropolitan Location of Firms and Households.” Public Finance Quarterly 22 (2), (1994): 139-167.

Lutkepohl, H. “Asymptotic Distribution of Impulse Response Functions and Forecast Error Variance Decompositions of Vector Autoregressive Models.” Review of Economics and Statistics 72 (1), (1990): 116-125.

Marques, C. R. “Inflation Persistence: Facts or Artefacts?” Working Paper Series, No. 371, European Central Bank, 2004.

Mirsky, L. An Introduction to Linear Algebra. Dover Publications, New York, 1990.

Munnell, A. "How Does Public Infrastructure Affect Regional Economic Performance?" New England Economic Review, Federal Reserve Bank of Boston, September/October, (1990): 11-32.

Munnell, A. "Policy Watch: Infrastructure Investment and Economic Growth.” Journal of Economic Perspectives 6 (4), (1992): 189-198.

Osterwald-Lenum, M. "A Note with Quantiles of the Asymptotic Distribution of the Maximum Likelihood Cointegration Rank Test Statistics." Oxford Bulletin of Economics and Statistics 54, (1992): 461-472.

Peterson, S., E. Jessup, and K. Casavant. "Freight Movements on Washington State Highways: Results of the 2003-2004 Origin and Destination Study." Strategic Freight Transportation Analysis Report \#10, School of Economic Sciences, Washington State University, 2004.

Reynolds, P. D. and W. Maki. "U.S. Regional Characteristics, New Firms, and Economic Growth." Working paper, University of Warwick, United Kingdom, 1990.

Scheines, R., P. Spirtes, C. Glymour, C. Meek, and T. Richardson. “The TETRAD Project: Constraint Based Aids to Causal Model Specification.” Multivariate Behavioral Research 33 (1), (1998): 65-117. 
Smith, L. J., J. S. Adams, J. L. Cidell, and B. J. Van Drasek. "Highway Improvements and Land Development Patterns in the Greater Twin Cities Area, 1970-1997: Measuring the Connections." CTS 02-03, Center for Transportation Studies, University of Minnesota, 2002.

Spirtes, P., C. Glymour, and R. Scheines. Causation, Prediction, and Search. Springer-Verlag, New York, 1993.

Stock, J. H. and M. W. Watson. "Vector Autoregressions." The Journal of Economic Perspectives 15 (4), (2001): 101-115.

Sturm, J. E., J. Jacobs, and P. Groote. "Output Effects of Infrastructure Investment in the Netherlands, 1853-1913.” Journal of Macroeconomics 21 (2), (1999): 355-380.

Tatom, J. A. "Public Capital and Private Sector Performance." Federal Reserve Bank of St. Louis Review 73, (1991): 3-15.

Toda, H.Y. and P. C. B. Phillips. "Vector Autoregressions and Causality.” Econometrica 61 (6), (1993): 1367-1393.

United States Bureau of Labor Statistics. Quarterly Census of Employment and Wages.

United States Bureau of Transportation Statistics. Highway Profile, 2002.

Vachal, K., J. Bitzan, and K. Button. "Transportation Quality Indices for Economic Analysis of Nonmetropolitan Cities.” DP-158, Upper Great Plains Transportation Institute, prepared for Bureau of Transportation Statistics, U.S. Department of Transportation, 2004.

Washington State Department of Health. Guidelines for Using Rural-Urban Classification Systems for Public Health Assessment, 2006.

Washington State Department of Transportation. Capital Program Management System.

Washington State Department of Transportation. Construction Contract Information System..

Yu, T. H., D. Bessler, and S. Fuller. "The Influence of Transportation Rates on Grain Prices: A Dynamic Analysis.” Presentation made at the Annual Meeting of the Transportation Research Forum, New York City, New York, March 23-25, 2006.

Steven K. Peterson, was graduate research associate in the Transportation Research Group at Washington State University in Pullman, WA, when this article was written. While at WSU he did research and analysis for the Strategic Freight Transportation Analysis (SFTA) project. Currently, he is a transportation geographer in the National Transportation Research Center of Oak Ridge National Laboratory in Knoxville, TN. His current research involves flow modeling of the U.S. railroad network.

Eric L. Jessup, is an assistant professor in the School of Economic Sciences at Washington State University in Pullman, WA. Eric has been a principal investigator with the Strategic Freight Transportation Analysis (SFTA) project. He was directly involved in the Eastern Washington Intermodal Transportation Study (EWITS) and spent nearly four years managing new product launches within the International Risk Management group at American Express. He is currently teaching and conducting research associated with freight transportation and logistics. 